\title{
Understanding quality of life and well-being for people living with
} advanced dementia.

\author{
Hughes, Sian; Woods, Robert; Algar-Skaife, Katherine; Jones, Catrin
}

\section{Nursing Older People}

DOI:

10.7748/nop.2019.e1129

Published: 22/03/2019

Peer reviewed version

Cyswllt i'r cyhoeddiad / Link to publication

Dyfyniad o'r fersiwn a gyhoeddwyd / Citation for published version (APA):

Hughes, S., Woods, R., Algar-Skaife, K., \& Jones, C. (2019). Understanding quality of life and well-being for people living with advanced dementia. Nursing Older People, 31(2), 18-24. https://doi.org/10.7748/nop.2019.e1129

\footnotetext{
Hawliau Cyffredinol / General rights

Copyright and moral rights for the publications made accessible in the public portal are retained by the authors and/or other copyright owners and it is a condition of accessing publications that users recognise and abide by the legal requirements associated with these rights.

- Users may download and print one copy of any publication from the public portal for the purpose of private study or research.

- You may not further distribute the material or use it for any profit-making activity or commercial gain

- You may freely distribute the URL identifying the publication in the public portal ?
}

Take down policy

If you believe that this document breaches copyright please contact us providing details, and we will remove access to the work immediately and investigate your claim. 


\title{
The Quality of life and well-being of individuals living with advanced dementia; resident, relative and staff perspectives: A case study
}

\section{Short title: Advanced dementia}

\begin{abstract}
The number of individuals living with advanced dementia in the care home sector is growing as people live longer. People living with advanced dementia have complex, individual needs and identifying contributors of their well-being is essential in maintaining and promoting their quality of life. Currently, little is known on quality of life and well-being in advanced dementia. A mixed method approach was used to understand the lived daily experience of residents with advanced dementia. The article presents a case study of two residents, " Graham and Martha". Methods include AwareCare observations, QUALID ratings and qualitative interviews with relatives and key staff members, gathered over a period of eight months. Although they both had limited verbal ability, they demonstrated the urge to communicate and non-vocal behaviours were used convey their feelings. The findings suggest that relatives are reassured/comforted where they see their relatives expressing themselves, and happier when they could maintain a regular caring role. Relatives also were appreciative of staff caring for the individual as a person. However, conflict was evident when care staff and relatives did not agree on what would be in the best interests of the person living with advanced dementia. Kitwood's personhood model was especially helpful in considering well-being in advanced dementia.
\end{abstract}

\section{Introduction}

Quality of life (QoL) has become increasingly recognised as an important goal in dementia care, underpinning healthcare policies and strategies. The latest Dementia Action Plan for Wales 2018-2022, p25 states that care homes need to be considered as an individual's home, and people have the right to 'live well'. According to the World Health Organisation (1995, p1) QoL is reliant on "the individual's perceptions of their position in life in the context of the culture and value system in which they live, and in relationship to their goals, expectations, and standards". There are now a number of QoL measures that have been used to enable people with dementia to indicate their subjective view of their QoL, but increasing cognitive impairment may make it challenging for individuals to self-report their own QoL 
(Bowling et al., 2015; Logsdon et al., 2002; Algar, Woods \& Windle, 2016). In advanced dementia, proxy-reports are an alternative, completed by family carers or by care-workers (Conde-Sala et al., 2010), consisting of direct observations or questionnaires or a mixture of both (Missotten et al., 2016). However, these beg the question as to what constitutes QoL in advanced dementia?

In this context, Lawton's framework (2004) is widely recognised (Netuveli \& Blane, 2008), combining the subjective, such as psychological well-being, with objective approaches such as the environment and behavioural competence (Netuveli \& Blane, 2008). The terms 'wellbeing' and QoL are often used interchangeably. Whilst we might observe that a person with advanced dementia appears to be happy, Ryff (1995) indicates that psychological well-being involves much more than happiness (see Box 1). These aspects may be more difficult to ascertain or even envisage in the context of severe impairments in cognition and communication, but in similar vein Kitwood (1992) summarises indicators of well-being in people living with dementia (see Box 2) as being characterised by feelings of worth, hope and agency, and by social confidence.

[Insert box $1 \& 2]$

An alternative but complementary perspective arises from a human rights perspective, building on the coming together of core values (see Box 3). The emphasis is on maintaining and promoting individuals' lifelong rights, promoting development and growth and working towards reducing ill-being (Kinderman, 2007; BPS, 2009). There is clear overlap with Kitwood's influential work on person-centred values (Kitwood, 1997), respecting and empowering the individual, but it also provides an ethical and legal framework (Kelly \& Innes, 2013), challenging inequality and the acceptance of less than excellent care for people living with dementia, simply because it has become standard practice (Kelly \& Innes, 2013). [Insert box 3]

Whilst conceptualising and measuring QoL in advanced dementia is challenging, some indications of features that may be important are emerging, such as psychological needs being met and the opportunity to take part in meaningful activity (Volicer, 2007). Social contact, interactions, and communication at a basic level including touch (Brooker, Snape, Johnson, Ward \& Payne, 1997) elicited responses, such as smiling, babbling, laughter, eye- 
gaze and reciprocity that have been termed as 'happy behaviour' (Astell \& Ellis, 2006; Ellis \& Astell, 2017).

As dementia progresses, many individuals require care home placement, and here purposely designed and adapted environments, providing relaxation and opportunities for personal contact can enhance QoL (Gillian et al., 2004). However, placement means leaving their family home, perhaps shared with loved ones, for a communal environment shared with strangers. This is also a transition for families, where they have been providing the care previously. Attention to the involvement of families, for example, through an understanding of the triangle of care, with family and care home staff working together has led to better outcomes for care recipients, families and care professionals (Royal College of Nursing, 2013).

\begin{abstract}
Aims
The aim of the research was to investigate the QoL and well-being of individuals living with advanced dementia in the care home sector. We aimed to explore residents' lived experiences in the care homes, their relatives' and their key staff members' perspectives of their quality of life and well-being and how this is expressed. Further, we aimed to investigate how human rights of residents are upheld and how family members and staff members deal with surrogate decision-making. These aims are pursued through two in-depth case studies of care home residents, Graham and Martha (pseudonyms) living with advanced dementia. We explore how helpful the different approaches to understanding QoL, well-being and human rights in advanced dementia are in practice and identify features that may be helpful in supporting these important outcomes.
\end{abstract}

\title{
Method
}

The research took place across two specialised dementia care homes, operated by an independent care home company in North Wales. The homes are divided into households of 8 to 12 residents, with each household providing care to individuals in different stages of dementia. Family members visit the households daily and an activities co-ordinator organises some activities. The study employed a mixed method approach, with data being collected 
through observations of residents in public areas of the care home, during 30-minute observations on 5 occasions. Further, in-depth, semi-structured interviews with care staff and families of residents were conducted alongside quantitative measures. The quality of life in late-stage dementia scale (QUALID) was completed independently by a family member and by a staff member. It comprises 11 items reflecting positive and negative components of observable mood and behaviour. Each item is rated on a five-point scale with lower scores indicating a higher QoL (Weiner et al., 2016). The AwareCare tool (Clare et al., 2012), is an observational tool, evaluating signs of awareness of residents living with advanced dementia, examining responsiveness to a variety of triggers in the social environment. Consent was obtained from relatives and care staff, but as the residents were unable to give consent, a personal consultee was approached to advise on their inclusion in the study. Here we focus on one resident from each home, from the ten who participated. The two cases were selected as they are living with advanced dementia within the same care home organisation, at two different homes. The cases focus attention on two very different individuals, with their own unique personalities and ways of expressing their happiness, affection, humour and distress.

\section{Case study one: Graham}

Graham was 88, had been diagnosed with dementia 6 years ago, living at the care home for twelve months. He was immobile, and it was usually late morning before he was brought to join the other residents in the lounge. During observation he appeared busy, often picking up objects to explore with his eyes and hands. When people stopped to interact with Graham, he was delighted, waving at them and blowing raspberries, eliciting a laugh in response. When there was no response, he proceeded to throw objects from his table; this brought a staffmember quickly over to him asking “Graham, what have you done?". Graham laughed, blew raspberries and pointed at her, blowing kisses and tapping on the side of his chair, apparently delighted. The majority of Graham's communication methods were non-verbal, and he displayed 'happy behavior', which consisted of smiling, laughing and blowing kisses when engaging with others (Astell \& Ellis, 2006). However, Graham's attempts to contribute socially were not always appreciated, as there was a possibility this could affect others on the household. At one point, Graham poured his drink onto the floor beside him and proceeded to bang his cup on the side of his chair.

The researcher used the 'Talking Mats' communication tool with Graham, presented on a tablet. He was very interested in the tablet itself, but made several attempts to move the cards 
across the screen into their different categories. He attempted to pick up the tablet to inspect the screen closely and nodded in response when the screen lit up on being touched. During the AwareCare tool assessment Graham reached out to hold the researcher's hands and shook them playfully, saying "wooo" and laughing loudly when the researcher laughed. He reached out and pinched the researcher's nose and gasped when she laughed; he gestured to his own nose with his hand and when the research touched the tip of his nose, he smiled, nodded and clapped.

Graham's wife, Lorna, arrived daily around lunch-time, bringing in different magazines and newspapers and reading them to him. He was a big sportsman and she flicked through to the sports pages with him. Graham was observed to study the newspaper and run his fingers across the photos and sometimes laughed at Lorna whilst she read. He pulled on the bottom of the newspaper and laughed when Lorna told him off playfully.

Lorna felt that becoming immobile had impacted on Graham's QoL and human rights. He was previously very active, sociable and enjoyed going out every day. His mobility had deteriorated following a fall and he had not been encouraged to walk during a 3-month hospital stay, before coming to the current care home. She explained that he would often respond with 'No', irrespective of the request, and this had been interpreted as a refusal; she felt that with encouragement and support he could have remained mobile. When Graham moved into the care home, Lorna was keen for Graham to receive physiotherapy, but the home considered that his condition was now too advanced to benefit. From the home's perspective, not to take his refusal at face value would be to detract from his human rights, but Lorna felt that this was not within his best interests, leading to some tension, but she felt she had to accept the situation.

Lorna explained Graham's attempts to interact: "oh he likes attention you know", "he's known to throw objects at times, he's easy to care for, but like everyone, he has his moments". Lorna enjoyed spending time with Graham at the home, but found it difficult: "I just don't see him the same as the others you know. He's different isn't he"? She observed other residents sleeping often, whilst Graham would be wide awake, calling out to others, desperate to interact. This made leaving him even more difficult. 
Stephanie, a Senior Care Assistant, explained that when Graham throws objects, it is not aggressive behaviour, she said 'you know he'll throw and he smiles, you can tell, he's got that cheeky twinkle in his eye”. To Stephanie it was his way of saying, "look at me", drawing attention to himself and initiating interaction with others, perhaps reducing boredom. Stephanie had also noticed that later in the day, around tea-time, when families had left, it was quiet on the household, with staff assisting residents to eat. At these times, while Graham was alone, he would throw his food, drink and any object nearby and become agitated. Stephanie felt that Graham was responding to a lack of stimulation in the environment "it's too quiet in here, it seems and maybe there's not enough going on tea time”. The staff recognised Graham's actions at tea-time, such as throwing, as an attempt to initiate interaction with others. Accordingly, the staff kept food aside, until they could sit with Graham and encourage him to eat independently. Making adjustments such as these allows the enjoyment of meal times, providing physical benefits and adding to overall QoL (Biernaki \& Barratt, 2001); nourishment is important for QoL, physically and psychologically. The removal of strict routines, allowing people to eat out of the 'set time zones' and responding to preferences, allows individuals to eat at preferred times, and in Graham's case enabled him to eat independently.

In summary, although Graham had little verbal communication, he used non-verbal communication extensively and with the support of his wife and the understanding of staff, his personhood was evident. On the QUALID scale, his wife and care staff rated his current QoL at the same level (21), despite Lorna's concern about no attempt being made to reduce his immobility. This is similar to the mean scores for care home residents with advanced dementia reported by Clare et al. (2014).

\section{Case study two: Martha}

Martha was 86 and had been diagnosed with dementia 4 years ago, living at the care home for the past 14 months. Her first language is Welsh. Martha was observed sitting with others in the living room smiling broadly when greeted by staff members. Martha initiated conversation with others, often mumbling but occasionally pronounced clear words. Martha called out "hurry", "come on en" and "bugger you" at the care staff and residents. At a mealtime, Martha gestured at others nearby her to eat, tapping the table and pointing towards their 
plates and pushing their plates towards them, taking on a mothering role. However, on other occasions, Martha's behaviour changed significantly and she appeared distressed. She was observed shouting in response to others or sitting alone in a separate room, with her arms folded and her head in her chest. During this time, Martha would refuse assistance from the care staff, shouting "shoo, shoo" and throwing her hands up in the air. Staff attributed these changes to recurrent urine infections.

The researcher, a Welsh speaker, used the 'Talking Mats' communication tool with Martha, presented on a tablet. Initially she was very interested in the screen, inspecting it closely, leaning over the screen. Martha let the researcher guide her hand over the screen to place different cards in different places "ooo" she said and laughed. During the AwareCare assessment Martha's took great interest in personal objects from her home that were presented to her. Martha would point at people in photographs and nod, feel and touch her soft toys, cushions and sometimes responded verbally, "ahh" "yes, yes" in Welsh. Martha would respond most times to her name being called, she would turn her head and explore the room, and shrug her shoulders.

Martha's family visited daily, speaking with Martha in Welsh. During a Welsh conversation, with her daughter Jo, she was observed to sit up, smiling broadly, her eyes open wide, fully immersed in the interaction. She made direct eye contact and nodded whilst Jo spoke with her, reciprocating vocally and non-vocally and reciting family members names.

Jo explained that care staff had taken time to understand Martha's personal history, "the staff know her you know like they can walk in now and tell you, how she is, what kind of person she is, they do know her, that helps us as well". Jo laughingly described her mother's character, "what she said went, you wouldn't dare disagree”. She enjoyed seeing aspects of her personality still evident, although not always easy for the staff. Jo discussed "it is important for us to make the most of it now while she is chatty like this, because there will come a time won't there where there will be no communication". Although Jo had reservations about Martha living at the care home, she talked about visiting and explained "It's nice to see her in good spirits, displaying ways she used to be. The way she was at home .. mischievous". Jo considered that the care her mother receives at the home contributed to their family's well-being and that the relationship with the care staff has made the journey easier for them. 
Martha's staff nurse, Gaynor, described Martha as a charming lady, compliant with care, who eats and drinks when physically well. Martha was vulnerable to urine infections, and during these times may be awake at night, refusing medication, food and fluids, inevitably prolonging her ill-being. Gaynor explained that at these times "She becomes frustrated, as a result of being unable to verbalise how she's feeling”. Gaynor felt Martha's family involvement was fundamental to her QoL, they were able to speak with her in her first language and encourage her to take her medications, eat and drink.

Overall, it is clear that Martha was able to communicate her feelings through vocal and nonvocal behaviours, and was able to verbalise more when with a person who could speak Welsh, her first language. Having a close family nearby, especially when Martha was unwell, was important to her well-being. On the QUALID scale Martha's daughter rated her QoL much more positively (17) than did staff (41). Martha's daughter expressed how important it was to see her mother as the individual she had always been, but this could be difficult for the staff, especially with her recurrent physical problems, which may have influenced the staff view of her QoL being less good.

\section{Discussion}

If we consider Graham and Martha from the perspective of Ryff's well-being framework, it is evident that both are seeking to exert control over their environment through their behaviour (environmental mastery) and that positive relationships are of prime importance. Acceptance, sense of purpose and self-growth are more difficult to judge. In terms of human rights, Identity emerges most strongly as a positive factor for both, with Graham's right to autonomy being reduced by his immobility. The relative lack of Welsh-speakers amongst the care home staff may be viewed as reflecting a lack of Fairness in meeting Martha's needs, but also impacting on her identity as a Welsh-speaker. In Kitwood's terms, both Graham and Martha show agency. Graham throws objects to achieve a response; Martha encourages her fellowresidents to eat. They are both socially confident, especially in relation to their relatives. Martha may show less hope and self-worth when she has a urine infection and is unwell and becomes distressed. Graham's self-worth is evident in the warmth of his relating, and lack of distress. Both demonstrated a number of Kitwood's indicators of well-being: e.g. initiating social contact, humour, self -expression, affectional warmth, social sensitivity and the ability 
to express a range of emotions. Kitwood's (1997) personhood theory suggests that personhood does not lie within the individual, but is supported by the presence of others, and this is evident for both Martha and Graham, whose individual personalities remain evident to family members and to staff who made the effort to get to know them well.

In addition to these perspectives on QoL and well-being, the unmet needs model of CohenMansfield et al. $(2007 ; 2015)$ is also relevant. People with advanced dementia may have decreased ability to communicate their needs, which are accordingly unrecognised and unmet. For Graham, calling out and throwing may act to alleviate boredom, a way of communicating his need for interaction and affirmation. For Martha, her distress may be communicating her discomfort, pain and illness.

\section{Learning Outcomes}

Individuals living with advanced dementia may have complex needs that require intervention. Advance care planning tends to focus on resuscitation and death and advance directives on individual daily care preferences are less common (Mitchell, 2004). Spending more time discussing advance care plans has been linked with higher family care satisfaction (Mitchell, 2004). Lorna clearly expressed her feelings about Graham's immobility and the lack of intervention he received. There is a negative perception, that individuals at this stage of their dementia journey do not have restorative potential. Despite these views, promoting and maintaining resident functional abilities for as long as possible contributes to QoL and decreased caregiver burden (Sandberg et al. 2002).

Advance care planning with the family can identify factors about the resident and provide deeper understanding of the individual. Martha's first language was Welsh and she had rarely spoken English. It was clear that Martha had a better understanding when addressed in her first language. At times, Gaynor explained, Martha could be non-compliant, and they had the benefit of having her daughters, who spoke with her in Welsh, which encouraged her to communicate, and take her medication. Although Martha may be unable to recognize her family members, having the opportunity to converse in Welsh supported her sense of safety, familiarity and comfort, which contributed to her overall QoL. Martha's difficulty in 
communicating in her second language, coupled with her illness, may have added to her psychological distress, impacting her well-being (Hamilton, 2008).

Language goes beyond the spoken word, as was evident in much of Graham's and Martha's daily behaviour. Discussing Graham's refusal to comply with physiotherapy in hospital, Lorna expressed that his 'no' was not a refusal, but his way of contributing to the conversation. Considering the congruence between an individual's behaviour and their verbal communication could improve decision making. Numerous research studies have placed emphasis on non-verbal behavioural cues, often supplementing verbalisation. Not only in dementia, non-vocal behaviours are used across a lifetime forming part of the individual's identity. They are an important form of communicating and comfort for families in the absence of verbal communication (Hamilton, 2008). Ignatieff (1999) wrote the following about his mother: "It (my mother's disease) changed my view of what a person is.... It taught me, to be less sentimental about memory as a carrier of human continuity. My mother had no memory whatever, but she was the same person." Jo also emphasised the importance of cherishing the moments she has with her mother, as she is now.

\section{Conclusions}

The case studies of Graham and Martha add to the evidence base on quality of life and wellbeing of people living with advanced dementia, an important area, which has received little attention or innovation in recent years. Through these case studies we have drawn on residents' daily lived experiences and the viewpoint of relatives and staff members, to further our understanding of quality of life and well-being of residents living with advanced dementia. Comparing a variety of perspectives, Kitwood's model is especially helpful in describing the experience of relatives and staff; despite limited verbal communication, the person remains, and with the support of others can experience well-being and QoL. 
Box 1. Psychological aspects of well-being (Ryff, 1995)

Sense of purpose

Self-growth

Acceptance

Mastery of the environment

Positive relationships

Autonomy

Box 3. FREIDA principles (Curtice \& Exworthy, 2010)

Fairness

Respect

Equality

Identity

Dignity

Autonomy
Box 2. Kitwood (1992) Indicators of wellbeing

Feelings of worth

Hope

Agency

Social confidence 


\section{References}

Algar, K., Woods, R. T., \& Windle, G. (2016). Measuring the quality of life and well-being of people with dementia: A review of observational measures. Dementia, 15(4), 832-857.

Astell, A. J., \& Ellis, M. P. (2006). The social function of imitation in severe dementia. Infant and Child Development: An International Journal of Research and Practice, 15(3), 311-319.

Bowling, A., Rowe, G., Adams, S., Sands, P., Samsi, K., Crane, M., ... \& Manthorpe, J. (2015). Quality of life in dementia: a systematically conducted narrative review of dementia-specific measurement scales. Aging \& mental health, 19(1), 13-31.

Biernacki, C., Ward, L., \& Barratt, J. (2001). Improving the nutritional status of people with dementia. British Journal of Nursing, 10(17), 1104-1114.

Brooker, D. J., Snape, M., Johnson, E., Ward, D., \& Payne, M. (1997). Single case evaluation of the effects of aromatherapy and massage on disturbed behaviour in severe dementia. British Journal of Clinical Psychology, 36(2), 287-296.

Clare, L., Whitaker, R., Quinn, C., Jelley, H., Hoare, Z., Woods, B., ... \& Wilson, B. (2012). AwareCare: development and validation of an observational measure of awareness in people with severe dementia. Neuropsychological rehabilitation, 22(1), 113-133.

Clare, L., Quinn, C., Hoare, Z., Whitaker, R., \& Woods, R. T. (2014). Care staff and family member perspectives on quality of life in people with very severe dementia in long-term care: a crosssectional study. Health and quality of life outcomes, 12(1), 175. 
Castro-Monteiro, E., Alhayek-Aí, M., Diaz-Redondo, A., Ayala, A., Rodriguez-Blazquez, C., RojoPerez, F., ... \& Forjaz, M. J. (2016). Quality of life of institutionalized older adults by dementia severity. International psychogeriatrics, 28(1), 83-92.

Cohen-Mansfield, J., Libin, A., \& Marx, M. S. (2007). Nonpharmacological treatment of agitation: a controlled trial of systematic individualized intervention. The Journals of Gerontology Series A: Biological Sciences and Medical Sciences, 62(8), 908-916.

Cohen-Mansfield, J., Dakheel-Ali, M., Marx, M. S., Thein, K., \& Regier, N. G. (2015). Which unmet needs contribute to behavior problems in persons with advanced dementia?. Psychiatry research, 228(1), 59-64.

Conde-Sala, J. L., Garre-Olmo, J., Turró-Garriga, O., Vilalta-Franch, J., \& López-Pousa, S. (2010). Differential features of burden between spouse and adult-child caregivers of patients with Alzheimer's disease: An exploratory comparative design. International journal of nursing studies, 47(10), 1262-1273.

Curtice, M. J., \& Exworthy, T. (2010). FREDA: a human rights-based approach to healthcare. The Psychiatrist, 34(4), 150-156.

Ellis, M., \& Astell, A. (2017). Communicating with people living with dementia who are nonverbal: The creation of Adaptive Interaction. PloS one, 12(8), e0180395.

Galik, E. M., Resnick, B., \& Pretzer-Aboff, I. (2009). 'Knowing what makes them tick': Motivating cognitively impaired older adults to participate in restorative care. International journal of nursing practice, 15(1), 48-55. 
Haesler, E., Bauer, M., \& Nay, R. (2007). Staff-family relationships in the care of older people: a report on a systematic review. Research in Nursing \& Health, 30(4), 385-398.

Hamilton, H. E. (2008). Language and dementia: Sociolinguistic aspects. Annual Review of Applied Linguistics, 28, 91-110.

Ignatieff, M. (1999). Berlin in autumn: The philosopher in old age. With comments by Robert Alter and Michael Andre Bernstein. Doreen B. Townsend Center Occasional Papers, no. 16.

Kelly, F., \& Innes, A. (2013). Human rights, citizenship and dementia care nursing. International Journal of Older People Nursing, 8(1), 61-70.

Kinderman, P. (2007). Human rights and applied psychology. Journal of community \& applied social psychology, 17(3), 218-228.

Kitwood, T. (1997). The concept of personhood and its relevance for a new culture of dementia care. London: Routledge.

Kitwood, T., \& Bredin, K. (1992). Towards a theory of dementia care: personhood and wellbeing. Ageing \& Society, 12(3), 269-287.

Mitchell, S. L., Kiely, D. K., \& Hamel, M. B. (2004). Dying with advanced dementia in the nursing home. Archives of internal medicine, 164(3), 321-326.

Missotten, P., Dupuis, G., \& Adam, S. (2016). Dementia-specific quality of life instruments: a conceptual analysis. International psychogeriatrics, 28(8), 1245-1262. 
Netuveli, G., \& Blane, D. (2008). Quality of life in older ages. British medical bulletin, 85(1), $113-$ 126.

Royal College of Nursing 2013: Understanding the needs of people with dementia and family carers. https://journals.rcni.com/doi/pdf/10.7748/nop.27.7.18.e699

Ryff, C. D. (1995). Psychological well-being in adult life. Current directions in psychological science, 4(4), 99-104.

Sandberg, J., Nolan, M. R., \& Lundh, U. (2002). 'Entering a New World': empathic awareness as the key to positive family/staff relationships in care homes. International Journal of Nursing Studies, 39(5), 507-515.

Volicer, L. (2007). Goals of care in advanced dementia: quality of life, dignity and comfort. The journal of nutrition, health \& aging, 11(6), 481.

Weiner, M. F., Martin-Cook, K., Svetlik, D. A., Saine, K., Foster, B., \& Fontaine, C. S. (2000). The quality of life in late-stage dementia (QUALID) scale. J Am Med Dir Assoc, 1(3), 114-6.

Welsh Government (2018). Written Statement - Dementia Action Plan for Wales 2018-2022. Accessed 22.09.2018.

https://gov.wales/about/cabinet/cabinetstatements/2018/dementiaactiomplan/?lang=en 